\title{
TASK 2.10 ADVANCED SAMPLING AND ANALYSIS OF FINE PARTICULATES
}

\author{
Final Topical Report \\ for the period January 1, 1997, through June 30, 1998 \\ (including semiannual for the period January 1, 1998, through June 30,1998)
}

Prepared for:

Federal Energy Technology Center

AAD Document Control

U.S. Department of Energy

PO Box 10940, MS 921-143

Pittsburgh, PA 15236

Cooperative Agreement No. DE-FC21-93MC30097--36

Performance Monitor: Don Krastman

Prepared by:

Donald P. McCollor

Kurt E. Eylands

Patricia L. Kleven

Energy \& Environmental Research Center

University of North Dakota

PO Box 9018

Grand Forks, ND 58202-9018

98-EERC-10-11

October 1998 


\section{DISCLAIMER}

This report was prepared as an account of work sponsored by an agency of the $U$ nited States Government. N either the U nited States Government, nor any agency thereof, nor any of their employees makes any warranty, express or implied, or assumes any legal liability or responsibility for the accuracy, completeness, or usefulness of any information, apparatus, product, or process disclosed or represents that its use would not infringe privately owned rights. Reference herein to any specific commercial product, process, or service by trade name, trademark, manufacturer, or otherwise does not necessarily constitute or imply its endorsement, recommendation, or favoring by the U nited States Government or any agency thereof. The views and opinions of authors expressed herein do not necessarily state or reflect those of the $U$ nited States Government or any agency thereof.

This report is available to the public from the National Technical Information Service, U.S. Department of Commerce, 5285 Port Royal Road, Springfield, VA 22161; phone orders accepted at (703) 487-4650.

\section{ACKNOWLEDGMENT}

This report was prepared with the support of the U.S. Department of Energy (DOE), Federal Energy Technology Center, however, any opinions, findings, conclusions, or recommendations expressed herein are those of the author(s) and do not necessarily reflect the view of the DOE.

\section{EERC DISCLAIMER}

LEGAL NOTICE This research report was prepared by the Energy \& Environmental Research Center (EERC), an agency of the University of North Dakota, as an account of work sponsored by the U.S. Department of Energy. Because of the research nature of the work performed, neither the EERC nor any of its employees makes any warranty, express or implied, or assumes any legal liability or responsibility for the accuracy, completeness, or usefulness of any information, apparatus, product, or process disclosed, or represents that its use would not infringe privately owned rights. Reference herein to any specific commercial product, process, or service by trade name, trademark, manufacturers, or otherwise does not necessarily constitute or imply its endorsement or recommendation by the EERC. 


\section{TABLE OF CONTENTS}

LIST OF FIGURES $\ldots \ldots \ldots \ldots \ldots \ldots \ldots \ldots \ldots \ldots \ldots \ldots \ldots \ldots \ldots$ ii

LIST OF TABLES $\ldots \ldots \ldots \ldots \ldots \ldots \ldots \ldots \ldots \ldots \ldots \ldots \ldots \ldots \ldots \ldots \ldots \ldots$

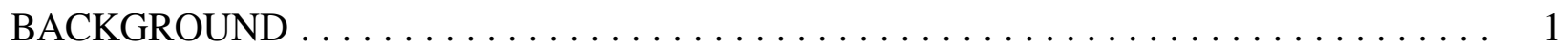

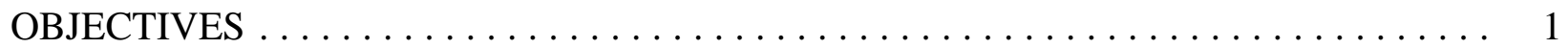

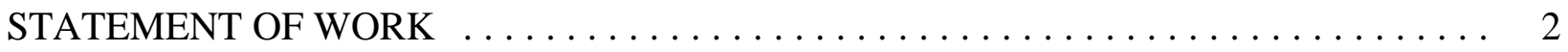

ACCOMPLISHMENTS $\ldots \ldots \ldots \ldots \ldots \ldots \ldots \ldots \ldots \ldots \ldots \ldots \ldots \ldots$

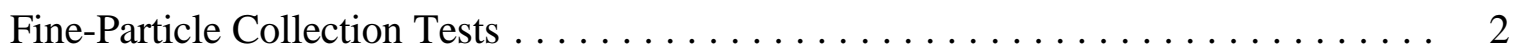

Improvement of Particle Analysis Methodology $\ldots \ldots \ldots \ldots \ldots \ldots \ldots \ldots \ldots$

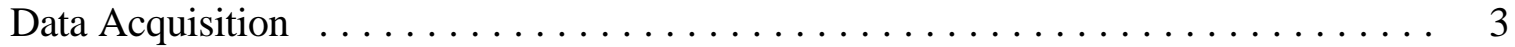

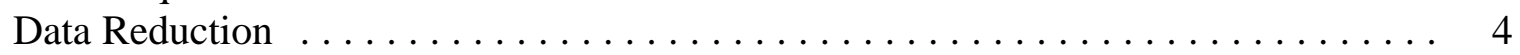

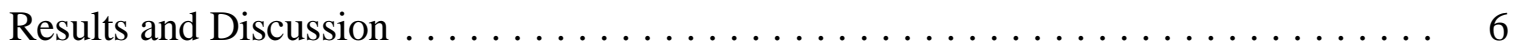

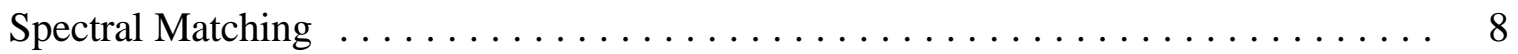

CONCLUSIONS $\ldots \ldots \ldots \ldots \ldots \ldots \ldots \ldots \ldots \ldots \ldots \ldots \ldots \ldots \ldots \ldots \ldots$

FUTURE PLANS $\ldots \ldots \ldots \ldots \ldots \ldots \ldots \ldots \ldots \ldots \ldots \ldots \ldots \ldots$ 


\section{LIST OF FIGURES}

1 A $0.6-\mu \mathrm{ma}_{2} \mathrm{SO}_{4}$ particle before analysis $\ldots \ldots \ldots \ldots \ldots \ldots \ldots \ldots \ldots \ldots \ldots \ldots \ldots$

2 The same particle after a $30-$ sec analysis $\ldots \ldots \ldots \ldots \ldots \ldots \ldots \ldots \ldots \ldots \ldots \ldots \ldots \ldots \ldots$

3 X-ray counts for $0.9-1.0-\mu \mathrm{m} \mathrm{KOH}$ particles $\ldots \ldots \ldots \ldots \ldots$

$4 \quad \mathrm{X}$-ray counts for $0.5-0.6-\mu \mathrm{m} \mathrm{KOH}$ particles $\ldots \ldots \ldots \ldots \ldots \ldots \ldots$

$5 \quad \mathrm{X}$-ray counts for $0.9-1.0-\mu \mathrm{m} \mathrm{NaCl}$ particles $\ldots \ldots \ldots \ldots \ldots \ldots \ldots$

$6 \quad \mathrm{X}$-ray counts for $0.5-0.6-\mu \mathrm{m} \mathrm{NaCl}$ particles $\ldots \ldots \ldots \ldots \ldots \ldots \ldots$

7 X-ray counts for $0.9-1.0-\mu \mathrm{Na}_{2} \mathrm{SO}_{4}$ particles $\ldots \ldots \ldots \ldots \ldots \ldots \ldots \ldots$

$8 \quad \mathrm{X}$-ray counts for $0.5-0.6-\mu \mathrm{Na}_{2} \mathrm{SO}_{4}$ particles $\ldots \ldots \ldots \ldots \ldots \ldots \ldots$

$9 \quad \mathrm{X}$-ray counts for $0.8-0.9-\mu \mathrm{m}\left(\mathrm{NH}_{4}\right)_{2} \mathrm{SO}_{4}$ particles $\ldots \ldots \ldots \ldots \ldots \ldots \ldots \ldots$

10 X-ray counts for $0.4-0.5-\mu m\left(\mathrm{NH}_{4}\right)_{2} \mathrm{SO}_{4}$ particles $\ldots \ldots \ldots \ldots \ldots \ldots \ldots \ldots \ldots$

\section{LIST OF TABLES}

1 Weight Percent and Standard Deviations for the Major Components of the Aerosols . . 7 


\section{TASK 2.10 ADVANCED SAMPLING AND ANALYSIS OF FINE PARTICULATES}

\section{BACKGROUND}

Regulations to minimize all pollutant emissions have been established to reduce the possible health hazards in all industries. These regulations require the reduction of sulfur oxides $\left(\mathrm{SO}_{\mathrm{x}}\right)$, nitrogen oxides $\left(\mathrm{NO}_{\mathrm{x}}\right)$, trace elements, and particulates when fossil fuels are burned. When fossil fuels are combusted, the particulate emissions are reduced by installing devices, such as electrostatic precipators (ESP), to trap particles that are still suspended in the gas stream. The majority of particulates are removed by these devices, with only the fine particulates, usually less than $1 \mu \mathrm{m}$, being emitted into the atmosphere. Thus the fine particulates that are emitted are of interest in this study. The advent of $\mathrm{PM}_{2.5}$ regulations has prompted an increased interest in the examination of secondary aerosols, which are a major component of poststack fine particulate material in the micron and submicron range. $\mathrm{NaCl}, \mathrm{Na}_{2} \mathrm{SO}_{4},\left(\mathrm{NH}_{4}\right)_{2} \mathrm{SO}_{4}, \mathrm{NH}_{4} \mathrm{NO}_{3}$, and $\mathrm{K}_{2} \mathrm{O}$ $(\mathrm{KOH})$ are the most common secondary aerosols encountered.

\section{OBJECTIVES}

The objectives of this study by the Energy \& Environmental Research Center (EERC) were to develop a sampling method to capture the fine particulates and classify the particulates according to their size and chemistry. When the sampling method is developed, two criteria need to be met: 1) the particulates are randomly dispersed on the sampling media and 2) the sampling media can be put directly into a scanning electron microscope (SEM) for analysis to prevent any alteration of the particulates. The SEM analysis, using the fine-particle technique (FPT), would provide the size, shape, and chemical composition of the individual fine particulates. The chemical composition will include ten elements ( $\mathrm{Na}, \mathrm{Mg}, \mathrm{Al}, \mathrm{Si}, \mathrm{P}, \mathrm{S}, \mathrm{K}, \mathrm{Ca}, \mathrm{Ti}, \mathrm{Fe}$ ) for each particulate. By using the chemical analysis, statistical tests will provide a system of classifying the particulates based on their size and chemistry, providing a better understanding of the type and size of particulates emitted.

The flood-related damage incurred in April 1997 included destruction of the existing SEM instruments as well as collected particulate samples and existing analysis records. Acquisition of replacement instruments occasioned a 6-month delay, with the new software incompatible with the existing FPT data acquisition programs.

The remaining project effort was directed at improving the FPT analysis methodology for secondary aerosols. The previously existing FPT analysis was not developed for, nor is well suited for, analysis of these particles. These improvements in the analysis methodology would take full advantage of the new instrument capabilities as well as provide essential groundwork for a DOE fine particulate project beginning in FY99. 


\section{STATEMENT OF WORK}

Several methods for sampling and analysis of fine particulates were to have been tested. Each sampling test would be analyzed using the FPT technique for collecting the size, shape, and chemical composition of 50 to 100 individual fine particulates. The FPT data then would be classified using cluster analysis and principal component analysis to provide a classification system for these particles.

Improving the FPT analysis method involved analysis of well-dispersed fine-particle reference samples of five compounds of principle importance as secondary aerosols to systematically determine optimum machine parameters and to evaluate classification of particles by a spectral matching technique versus the conventional elemental quantification used by the older FPA (fine-particle analysis) method.

\section{ACCOMPLISHMENTS}

\section{Fine-Particle Collection Tests}

Early in the project, particulate samples were collected using the advanced hybrid particulate collector (AHPC) on the inlet port of the particulate test combustor (PTC) when an Absaloka coal was burned in early April 1997. The samples were collected at the inlet rather than the outlet port because of the loading that was expected and the temperature at which the PTC was run. Samples at the inlet were expected to see a much greater particulate loading than at the outlet because of the efficiency of the particulate collection device on the PTC. Also, polycarbonate filters cannot withstand temperatures above $230^{\circ} \mathrm{C}$ for long periods of time; therefore, a quick loading time was required. The samples were briefly scanned and photographed using the SEM to determine the best particulate loading time. The particulates were too close together on the 20- and 30-sec sampling time polycarbonate filters to be able to analyze individual

particles. The particle dispersion on a vitreous carbon substrate appeared to be the best of the four samples.

These samples were ready for FPT analysis, but because of the April 1997 flood damage to the analytical equipment, the analyses were unable to be completed, and photographic as well as other experimental records were also lost. Installation of replacement SEM instruments was completed in December 1997, and particulate analysis programs for use on the instruments were rewritten and verified. This resulted in a direct 6-8 month delay in the project.

\section{Improvement of Particle Analysis Methodology}

The advent of $\mathrm{PM}_{2.5}$ regulations have prompted an increased interest in the examination of secondary aerosols, which are a major component of poststack fine particulate material in the micron and submicron range. $\mathrm{NaCl}, \mathrm{Na}_{2} \mathrm{SO}_{4},\left(\mathrm{NH}_{4}\right)_{2} \mathrm{SO}_{4}, \mathrm{NH}_{4} \mathrm{NO}_{3}$, and $\mathrm{K}_{2} \mathrm{O}(\mathrm{KOH})$ are the most common secondary aerosols encountered. The previously existing FPT analysis was not developed for, and is not well suited for, analysis of these materials. The new program direction 
was to produce pure dispersions of these compounds in the micron-to-submicron size range directly on a vitreous carbon substrate to develop and assess SEM measurement and quantification techniques.

Aerosols were produced from pure $1.0 \mathrm{M}$ aqueous solutions of $\mathrm{NaCl}, \mathrm{Na}_{2} \mathrm{SO}_{4},\left(\mathrm{NH}_{4}\right)_{2} \mathrm{SO}_{4}$, $\mathrm{NH}_{4} \mathrm{NO}_{3}$, and $\mathrm{K}_{2} \mathrm{O}(\mathrm{KOH})$ using a Tri-Jet Model 3460 aerosol generator and collected by direct impingement on a vitreous carbon substrate. Good dispersion with nearly all particulate size below $2 \mu \mathrm{m}$ and the majority in the $0.1-\mu \mathrm{m}$ range was achieved with a substrate collection time of 2-3 minutes. Additional reference standards of the materials were prepared by allowing large drops to evaporate on vitreous carbon substrates. The samples could be introduced directly into the SEM for analysis with no prior carbon coating or other preparation and analyzed with minimal charging of the samples.

\section{Data Acquisition}

The equipment used for this work was a JEOL 5800LV Series SEM equipped with a NORAN Instruments Voyager IV microanalyzer and a NORAN Instruments Pioneer energydispersive $\mathrm{x}$-ray detector system (EDS). The x-ray detector is equipped with a NORVAR thin window to allow light element detection.

The first parameters to be determined were the physical machine parameters such as the accelerating voltage, beam current, magnification, counting time, and working distance which allowed for the greatest reliability or reproducibility of the acquired data.

The following optimum parameters were determined based on the sample type, magnifications required, and energy requirements for x-ray generation:

- Accelerating voltage: $5 \mathrm{kV}$

- Beam current: $\quad 300$ pA

- Magnification: $15000 \times$

- Working distance: $10 \mathrm{~mm}$

- Counting time: $\quad 30 \mathrm{sec}$

The accelerating voltage was kept to a minimum to minimize the excitation volume or the volume of x-ray generation to the smallest level that still allowed the generation of x-rays for the elements contained in the aerosols generated for this work. Elements with an atomic number greater than 20 (greater than calcium) such as titanium and iron could not be detected with this accelerating voltage. Since the highest atomic number element used in these samples was potassium (K, no. 19), an acceleration voltage of $5 \mathrm{kV}$ was the minimum value acceptable. Accelerating voltages of 10,7 , and $3 \mathrm{kV}$ were also tried. The higher accelerating voltages would be appropriate for measurement of higher atomic number compounds but were not necessary for the aerosol compounds used for this work.

The beam current of $300 \mathrm{pA}$ was derived as a compromise between being able to image at the required magnification and the ability to detect X-rays emitted from the sample: the lower the 
beam current, the finer or the smaller the cross-sectional area of the electron beam. Extremely fine beam sizes are required for high magnification imaging but are very poor for x-ray generation because of the small area excited at the surface of the sample. Beam currents in the range of 100 to $600 \mathrm{pA}$ were tried. At $100 \mathrm{pA}$, the $\mathrm{x}$-ray generation was poor, and at $600 \mathrm{pA}$, the $15,000 \times$ image was not as sharp as needed for the particle sizing.

A magnification of $15,000 \times$ was used because the sizing technique is based on the area of the pixels that make up the image of that particle. Since all images collected were 512 by 512 pixels, higher magnifications result in more pixels defining the particle, therefore increasing the accuracy of the sizing. However, because of other machine parameters, especially accelerating voltage and beam current, magnifications higher than $15,000 \times$ lose resolution. When this happens, the particle edges become fuzzy, and sizing is not as consistent since the edges are difficult to define.

Counting times were based mainly on the rate of destruction of the sample. $\mathrm{KOH}$ was the most resistant to beam damage, and $\left(\mathrm{NH}_{4}\right) \mathrm{NO}_{3}$ was so easily damaged that a complete spectrum could not be properly collected. A count time of $30 \mathrm{sec}$ was used based on the amount of beam destruction to a $0.5-\mu \mathrm{m} \mathrm{NaCl}$ particle. $\mathrm{NaCl}$ was about intermediate in beam destruction with $\mathrm{Na}_{2} \mathrm{SO}_{4}$ being slightly more resistant and $\left(\mathrm{NH}_{4}\right)_{2} \mathrm{SO}_{4}$ being somewhat less resistant. Figures 1 and 2 show the beam damage to a $\mathrm{Na}_{2} \mathrm{SO}_{4}$ particle after $30 \mathrm{sec}$ of electron bombardment. The actual destruction time of each of the compounds was not accurately determined. Several particles from each of the aerosols were examined after $30 \mathrm{sec}$, and the degree of destruction was noted.

\section{Data Reduction}

Because of the unreliability of light element standards and the particles analyzed being smaller than the electron beam, a method of spectral matching was used compared with the standard method of quantitation. Spectral matching was developed for thin-film analysis of light elements and does not rely on standards but matches the entire spectrum, or portion of the spectrum, to those spectra stored in a database. The unknown spectra are compared against known spectra, and the best matches are reported.

The aerosols used for this work were produced from pure 1.0 M aqueous solutions on a vitreous carbon substrate and were used to create the database to which unknown particles were matched. 100 spectra were collected representing particles ranging in size from 0.1 to $1.0 \mu \mathrm{m}$ for each of the $\mathrm{KOH}, \mathrm{NaCl}$, and $\mathrm{Na}_{2} \mathrm{SO}_{4}$ samples. Only 50 spectra of the $\left(\mathrm{NH}_{4}\right)_{2} \mathrm{SO}_{4}$ were collected and saved because particles less than $0.3 \mu \mathrm{m}$ did not produce a detectable signal. No spectra were saved from the $\left(\mathrm{NH}_{4}\right) \mathrm{NO}_{3}$ sample. Several attempts were made with various sizes of particles, including an area several $\mathrm{mm}$ across, but no signal other than from the carbon substrate and a minor amount of oxygen could be detected. Spectra were collected down to the $0.1-\mu \mathrm{m}$ particle size for each of the materials with the number of x-ray counts produced in the order $\mathrm{NaCl}>$ $\mathrm{Na}_{2} \mathrm{SO}_{4}>\mathrm{KOH}$. 


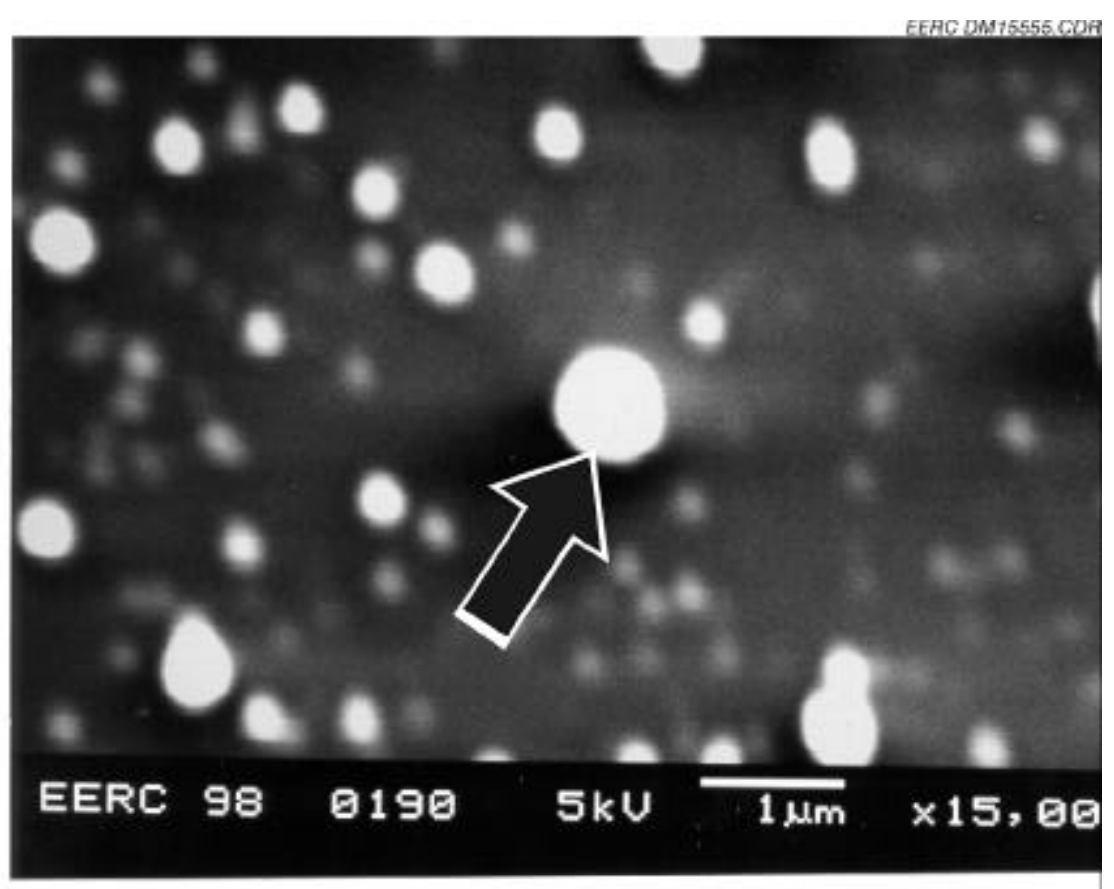

Figure 1. A 0.6- $\mu \mathrm{m} \mathrm{Na} \mathrm{SO}_{4}$ particle before analysis.

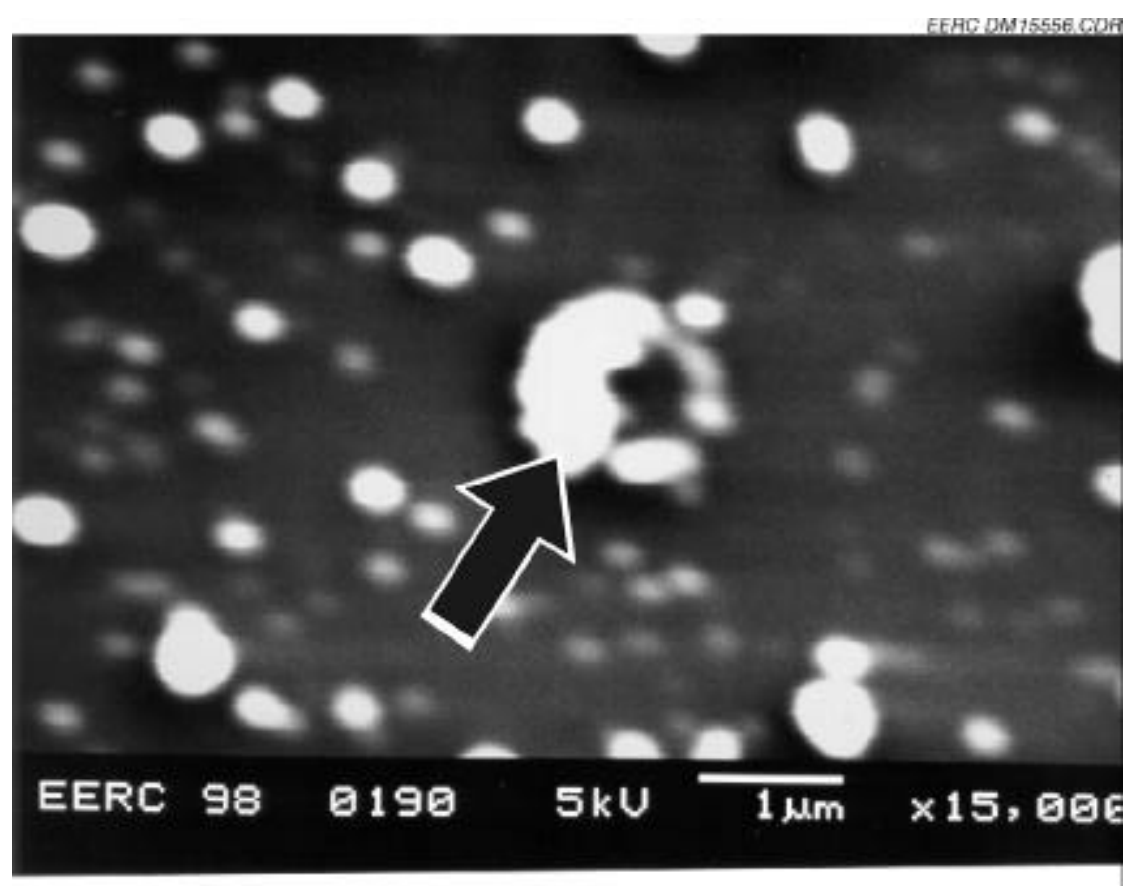

Figure 2. The same particle after a 30-sec analysis. 


\section{Results and Discussion}

Once the physical parameters for spectral acquisition of aerosol fine particles were determined, several aspects of using this technique for fine-particle analysis were explored:

1. The ability to quantify nitrogen and oxygen in the particulate was found to be poor because of their volatility and the lack of standards. Oxygen is easily detected but is not quantified using conventional quantification techniques such as ZAF which quantifies an unknown peak based on the number of x-ray counts as compared to a standard with a known weight percent of the element to be quantified. Oxygen is commonly determined either by difference, meaning that the sum of the other element weight percents are subtracted from 100, or by stoichiometry, which calculates the weight percent of oxygen by assuming that all of the elements detected are in their oxide form. By using spectral matching, oxygen is not quantified, but the height and shape of the oxygen peak are compared to other oxygen peaks stored in the spectral database. Nitrogen was not detected in either the $\left(\mathrm{NH}_{4}\right)_{2} \mathrm{SO}_{4}$ or $\mathrm{NH}_{4} \mathrm{NO}_{3}$ samples.

2. The possibility of using wavelength-dispersive techniques (WDS) was not considered for this work because of the high accelerating voltage and beam current requirements needed to measure x-ray wavelengths. An accelerating voltage of $25 \mathrm{kV}$ and a beam current of $10 \mathrm{nA}$ may work for less volatile compounds, but was not practical for aerosol samples.

3. Accuracy and reproducibility as a function of particle size were investigated by calculating the average weight percent and standard deviation for the major components in each of the aerosols. Table 1 shows the principal components, the average weight percent, and standard deviation of each of the major elements in $0.1-\mu \mathrm{m}$ size intervals. In general, the standard deviation tends to increase with a decrease in particle size. Potassium was the heaviest element analyzed in this data set and shows the greatest reproducibility. Lighter elements show a much greater variation. Sodium from $\mathrm{NaCl}$ shows less variation than $\mathrm{Na}$ from $\mathrm{Na}_{2} \mathrm{SO}_{4}$. Sulfur also shows a higher deviation as the particles become smaller.

4. A technique of fine-particle measurement by pixel size was used for these measurements. The technique relies on Feature Sizing with Chemical Typing software from NORAN Instruments which sizes particles by summing the area of all of the pixels that define a particle. An SEM image of the particles to be sized is acquired which is then processed to create a binary image of the particles to be sized and/or analyzed. A binary image is simply an image in which pixels are either on or off, creating a black or white image with no shades of grey. The area of the pixels that are on or white is the area of the particle being sized. The pixel area is calibrated to the SEM magnification and changes with magnification accordingly. Image distortion causes results to vary because the particle edge is not distinct and is arbitrarily picked to occur at some intermediate grey level as the pixels of the original image grade from white (high intensity) to black (low intensity) over a distance. An image with little or no distortion 
TABLE 1

Weight Percent and Standard Deviations for the Major Components of the Aerosols

\begin{tabular}{|c|c|c|c|c|c|c|c|c|}
\hline \multirow[t]{2}{*}{ Size } & & \multicolumn{2}{|c|}{$\mathrm{KOH}$} & \multicolumn{2}{|c|}{$\mathrm{NaCl}$} & \multicolumn{2}{|c|}{$\mathrm{Na}_{2} \mathrm{SO}_{4}$} & \multirow{2}{*}{$\frac{\left(\mathrm{NH}_{4}\right)_{2} \mathrm{SO}_{4}}{\mathrm{~S}}$} \\
\hline & & K & $\mathrm{O}$ & $\mathrm{Na}$ & $\mathrm{Cl}$ & $\mathrm{Na}$ & $S$ & \\
\hline Theoretical & & 70.96 & 29.04 & 39.34 & 60.66 & 32.37 & 22.57 & 25.84 \\
\hline \multirow{2}{*}{0.9 to 1.0} & $\mathrm{av}$ & 66.5 & 29.2 & 32.9 & 62.3 & 39.3 & 20.7 & 95.6 \\
\hline & std & 4.0 & 1.9 & 2.1 & 1.9 & 7.6 & 3.7 & 2.5 \\
\hline \multirow{2}{*}{0.8 to 0.9} & av & 67.7 & 28.0 & 29.5 & 66.7 & 45.6 & 19.8 & 91.2 \\
\hline & std & 6.6 & 5.5 & 2.8 & 3.7 & 13.2 & 2.9 & 8.8 \\
\hline \multirow{2}{*}{0.7 to 0.8} & av & 64.6 & 31.2 & 30.3 & 65.3 & 47.9 & 18.1 & 87.4 \\
\hline & std & 6.3 & 4.9 & 4.1 & 5.6 & 10.5 & 3.6 & 13.5 \\
\hline \multirow{2}{*}{0.6 to 0.7} & av & 63.2 & 31.5 & 27.7 & 67.0 & 49.8 & 15.6 & 81.1 \\
\hline & std & 4.8 & 4.9 & 3.0 & 3.3 & 8.5 & 4.6 & 14.2 \\
\hline \multirow{2}{*}{0.5 to 0.6} & $\mathrm{av}$ & 66.1 & 29.2 & 23.4 & 68.5 & 50.7 & 14.5 & 56.9 \\
\hline & std & 3.5 & 2.9 & 3.1 & 5.6 & 7.6 & 5.3 & 21.7 \\
\hline \multirow{2}{*}{0.4 to 0.5} & av & 67.5 & 26.8 & 26.2 & 63.7 & 58.9 & 16.8 & 74.4 \\
\hline & std & 2.8 & 2.4 & 6.0 & 7.6 & 18.9 & 9.7 & 24.1 \\
\hline \multirow{2}{*}{0.3 to 0.4} & $\mathrm{av}$ & 71.8 & 20.9 & 24.2 & 68.1 & 53.6 & 17.2 & 68.4 \\
\hline & std & 2.9 & 3.3 & 2.7 & 4.7 & 18.0 & 10.6 & 26.2 \\
\hline \multirow{2}{*}{0.2 to 0.3} & av & 74.1 & 16.0 & 24.0 & 67.1 & 58.6 & 10.3 & \\
\hline & std & 4.9 & 2.7 & 4.4 & 8.2 & 13.9 & 11.3 & \\
\hline \multirow{2}{*}{0.1 to 0.2} & av & 69.9 & 12.7 & & & 50.6 & 7.2 & \\
\hline & std & 2.65 & 3.4 & & & 19.0 & 8.7 & \\
\hline
\end{tabular}

has distinct particle boundaries, and the gradation from white to black, is complete over a very short distance. Alternatively, a distorted image with poorly defined particle edges may have several pixels of various grey levels making that transition from white to black, and some arbitrary value will be assigned by the operator to define the boundary edge for the binary image. The sizing of particles by pixel measurement is very fast and consistent as compared to other methods of particle measurement such as measuring the diameter 
of the aerosol particles and calculating an area. Large numbers of particles can be sized quickly and accurately provided the SEM image is adequate.

5. The relationship of signal-to-particle volume was plotted for each of the size ranges. Since the electron beam size at $300 \mathrm{pA}$ is approximately $0.6 \mu \mathrm{m}$ in diameter, entire particles and a portion of the substrate on which the particles are mounted will emit xrays. The total number of $\mathrm{x}$-ray counts derived from the carbon substrate was plotted along with the sum of the counts of the aerosol components for $0.1-\mu \mathrm{m}$ intervals. Figures 3 and 4 show that for $\mathrm{KOH}$ there is a degree of consistency in the total number of counts for the large and intermediate size ranges. Figures 5 and 6 show more variability for the $\mathrm{NaCl}$ sample. Figure 5 shows that the total x-ray counts for $\mathrm{NaCl}$ for the larger sizes are greater than the substrate counts. $\mathrm{NaCl}$ has the strongest signal for the particle sizes of all of the aerosols. This is due in part to the atomic number of both components ( $\mathrm{Na}$ and $\mathrm{Cl}$ ) being capable of producing strong signals. Figures 7 and 8 show a consistency in the aerosol counts with a rather variable total number of $\mathrm{x}$-ray counts for $\mathrm{Na}_{2} \mathrm{SO}_{4}$. For the $\left(\mathrm{NH}_{4}\right)_{2} \mathrm{SO}_{4}$ aerosol, the 0.8- to 0.9- $\mu \mathrm{m}$ range in Figure 9 shows a variable number of total counts and a low, but fairly consistent number of counts for the particles. Figure 10 shows that in the 0.4- to $0.5-\mu \mathrm{m}$ range for $\left(\mathrm{NH}_{4}\right)_{2} \mathrm{SO}_{4}$, the total counts are high, and the particle counts are extremely low.

\section{Spectral Matching}

Spectra were collected and stored in a spectral match database for comparison with unknown spectra. The matching techniques work well for each aerosol when checked against itself. When mixed aerosols were matched against the database, the carbon peak dominated, especially for the smaller particles, and the matching technique was ineffective. This method still shows some promise for the identification of aerosols based on portions of the spectra used in conjunction with total x-ray counts generated from the particles.

\section{CONCLUSIONS}

Sampling tests indicated that the polycarbonate filters were marginally acceptable for instack fine-particle collection because of their $230^{\circ} \mathrm{F}$ melting point as well as requiring carbon coating to reduce charging effects. Vitreous carbon substrates, although not porous, have acceptable thermal stability as well as acceptable levels of charging. A porous silver membrane filter is also being considered for future testing.

Pure reference samples of secondary aerosols have been successfully been collected on vitreous carbon substrates with good dispersion and found suitable for direct examination by SEM without prior coating or preparation.

These samples will be used to develop optimum SEM measurement and quantification techniques related to the analysis of fine secondary aerosols. 


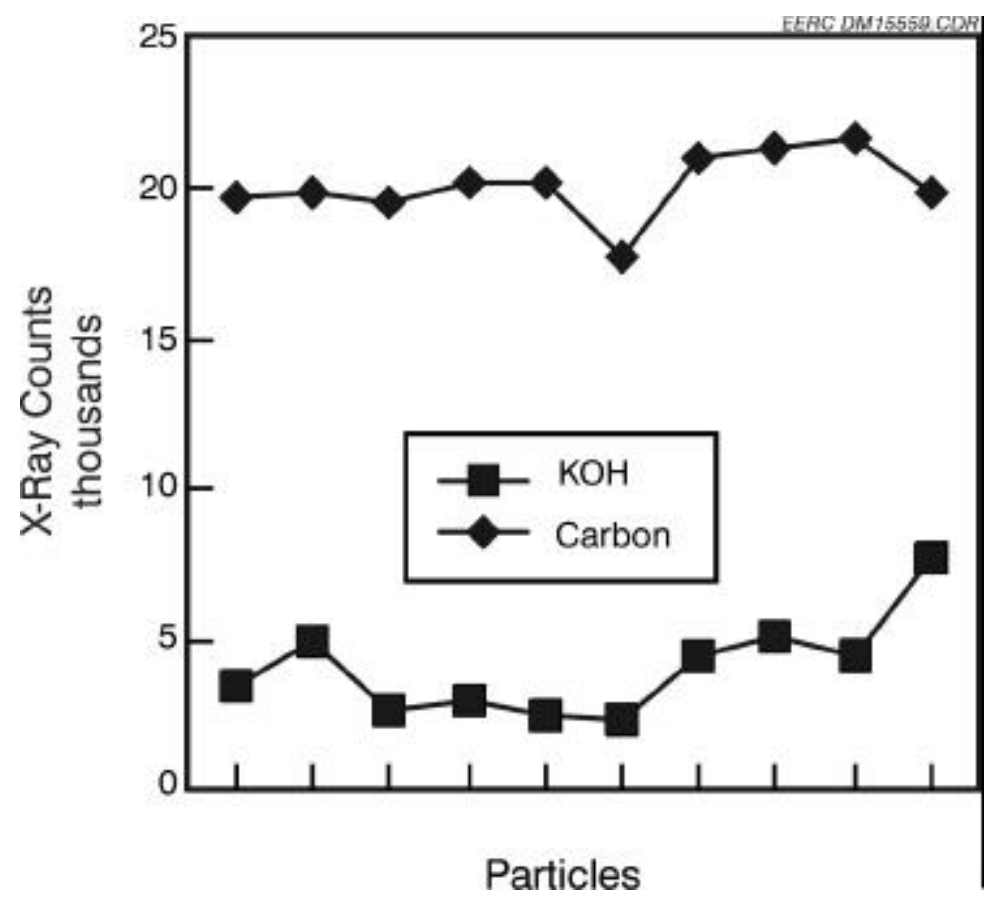

Figure 3. X-ray counts for $0.9-1.0-\mu \mathrm{m} \mathrm{KOH}$ particles

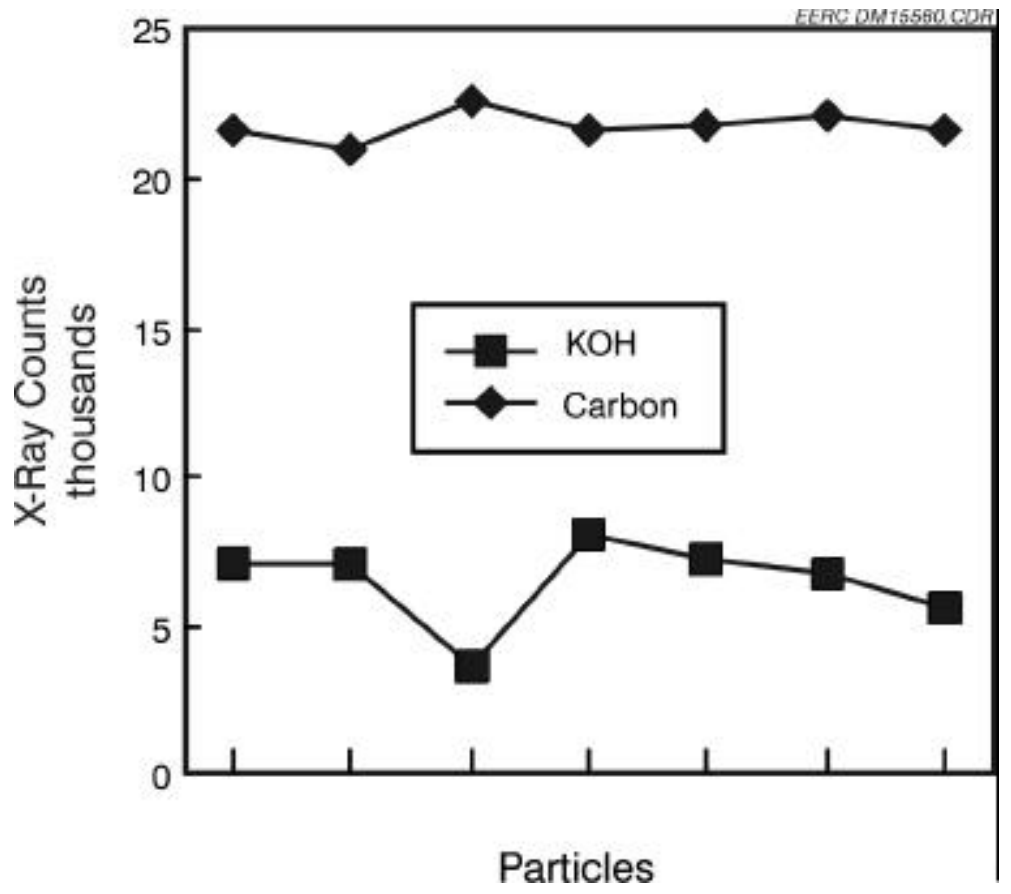

Figure 4. X-ray counts for $0.5-0.6-\mu \mathrm{m} \mathrm{KOH}$ particles. 


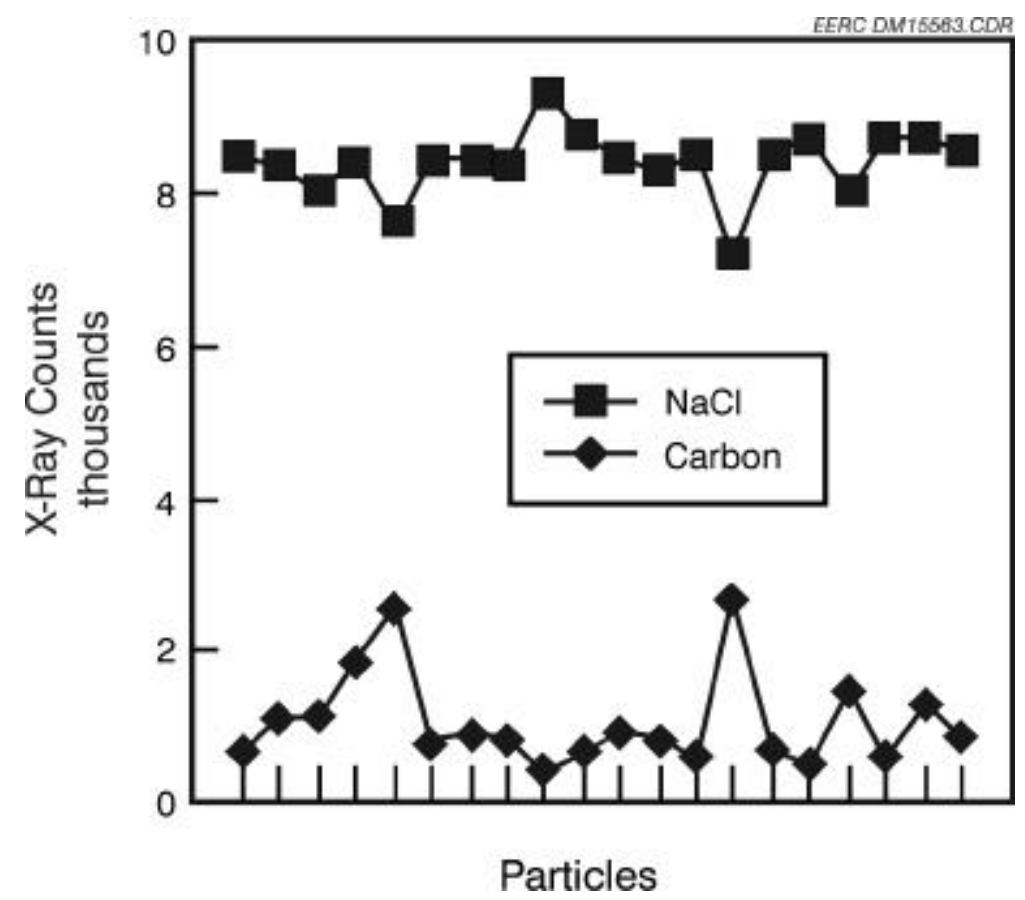

Figure 5. X-ray counts for $0.9-1.0-\mu \mathrm{m} \mathrm{NaCl}$ particles.

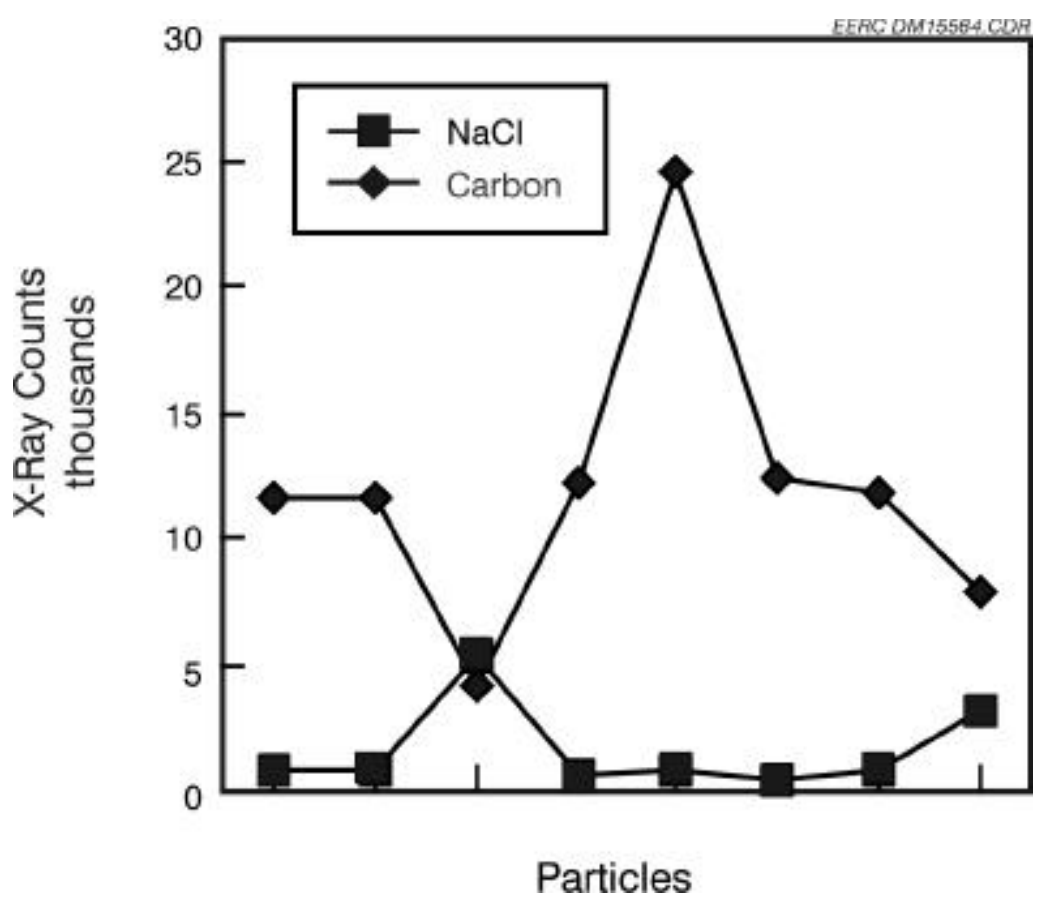

Figure 6. X-ray counts for $0.5-0.6-\mu \mathrm{m} \mathrm{NaCl}$ particles. 


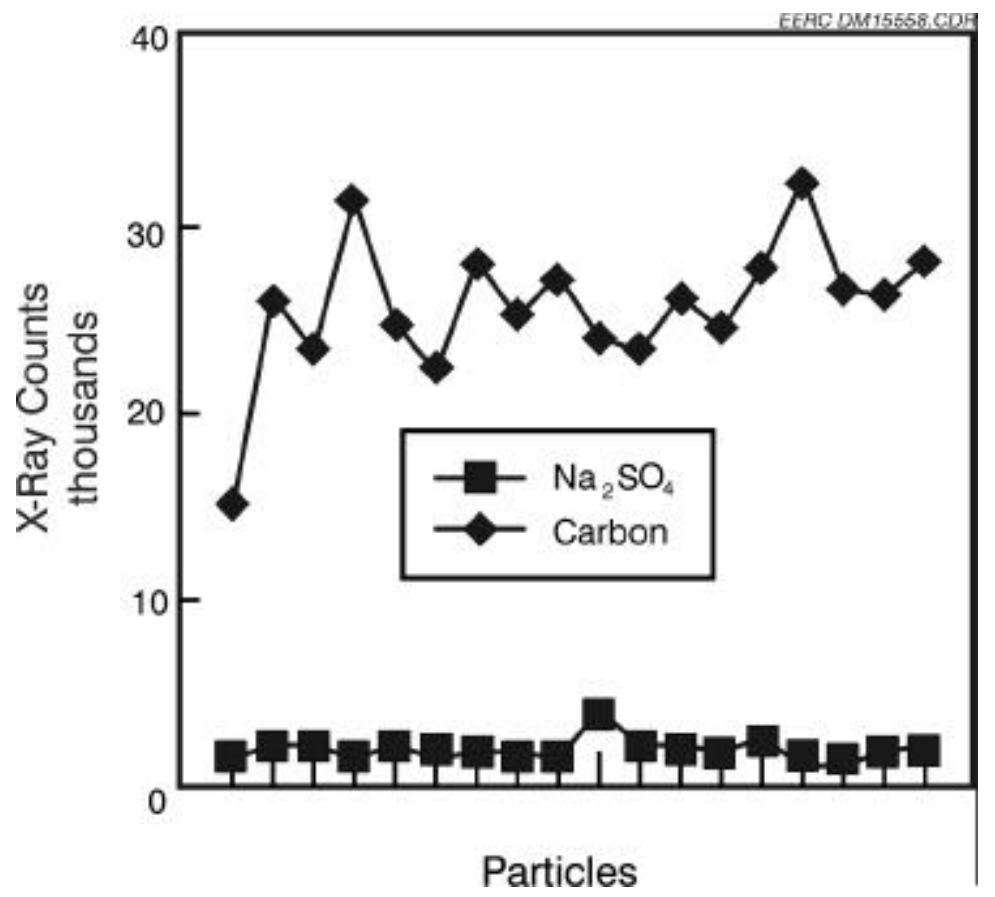

Figure 7. X-ray counts for $0.9-1.0-\mu \mathrm{m} \mathrm{Na}{ }_{2} \mathrm{SO}_{4}$ particles.

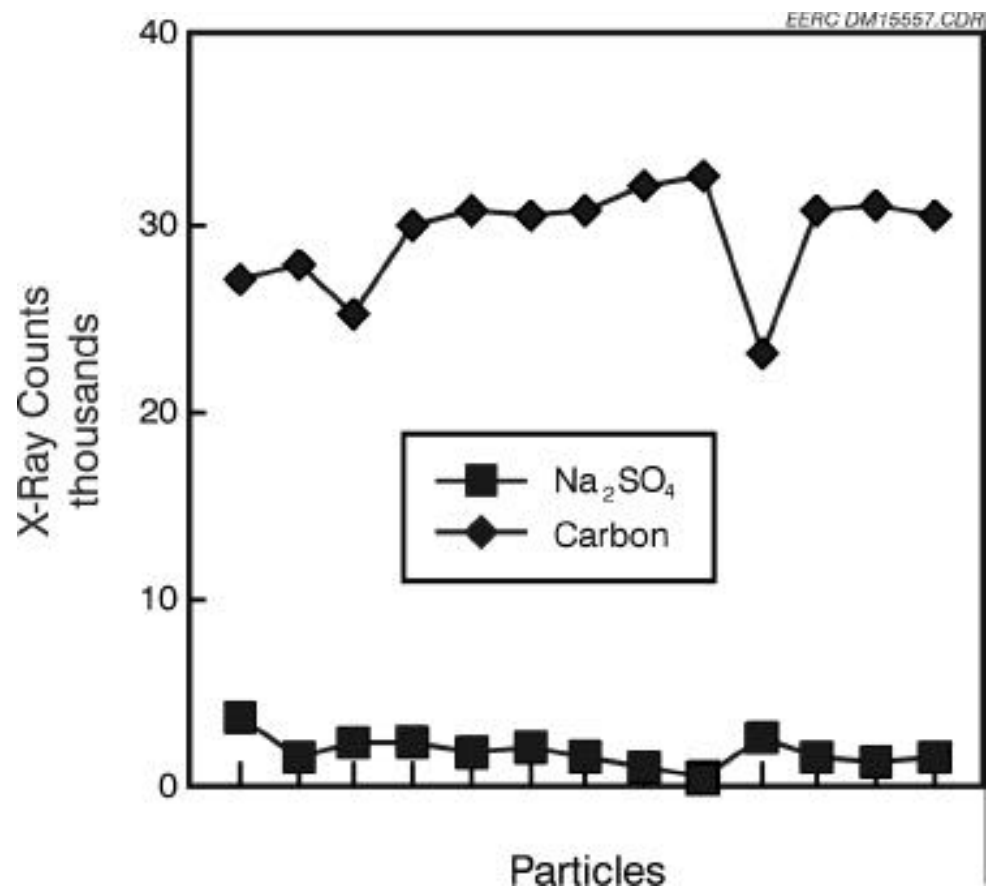

Figure 8. X-ray counts for $0.5-0.6-\mu \mathrm{m} \mathrm{Na}_{2} \mathrm{SO}_{4}$ particles. 


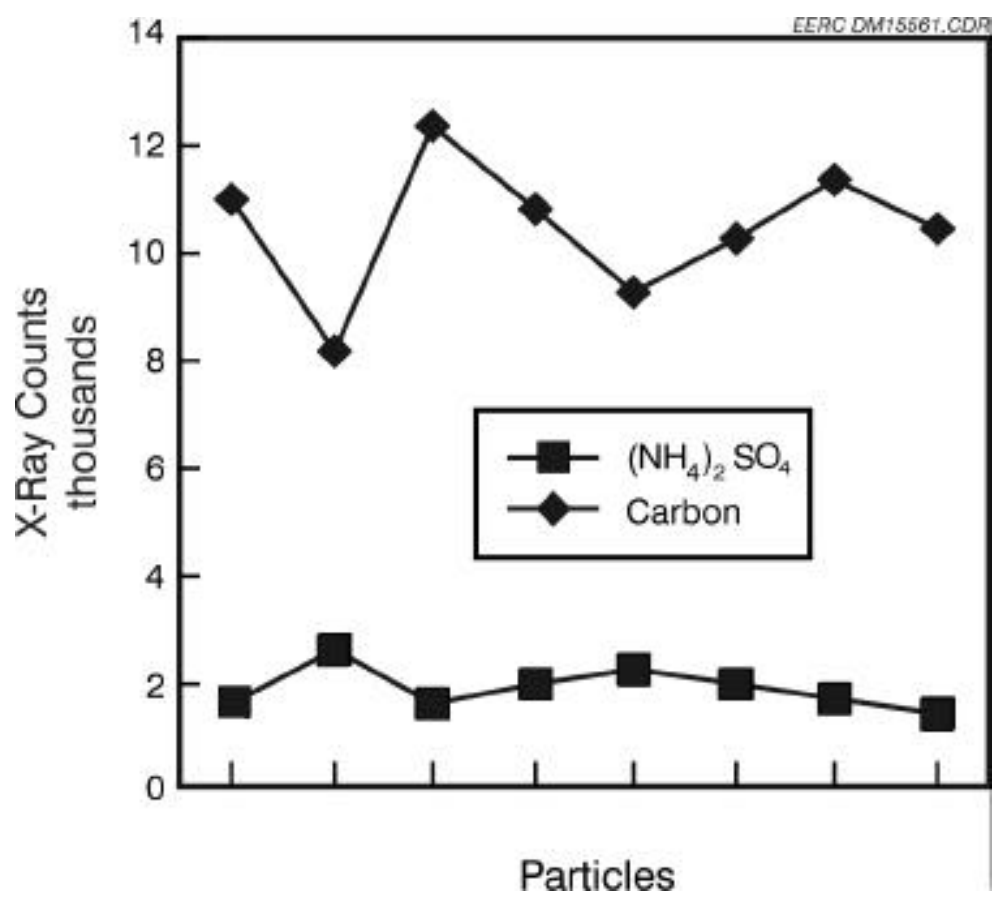

Figure 9. X-ray counts for $0.8-0.9-\mu \mathrm{m}\left(\mathrm{NH}_{4}\right)_{2} \mathrm{SO}_{4}$ particles.

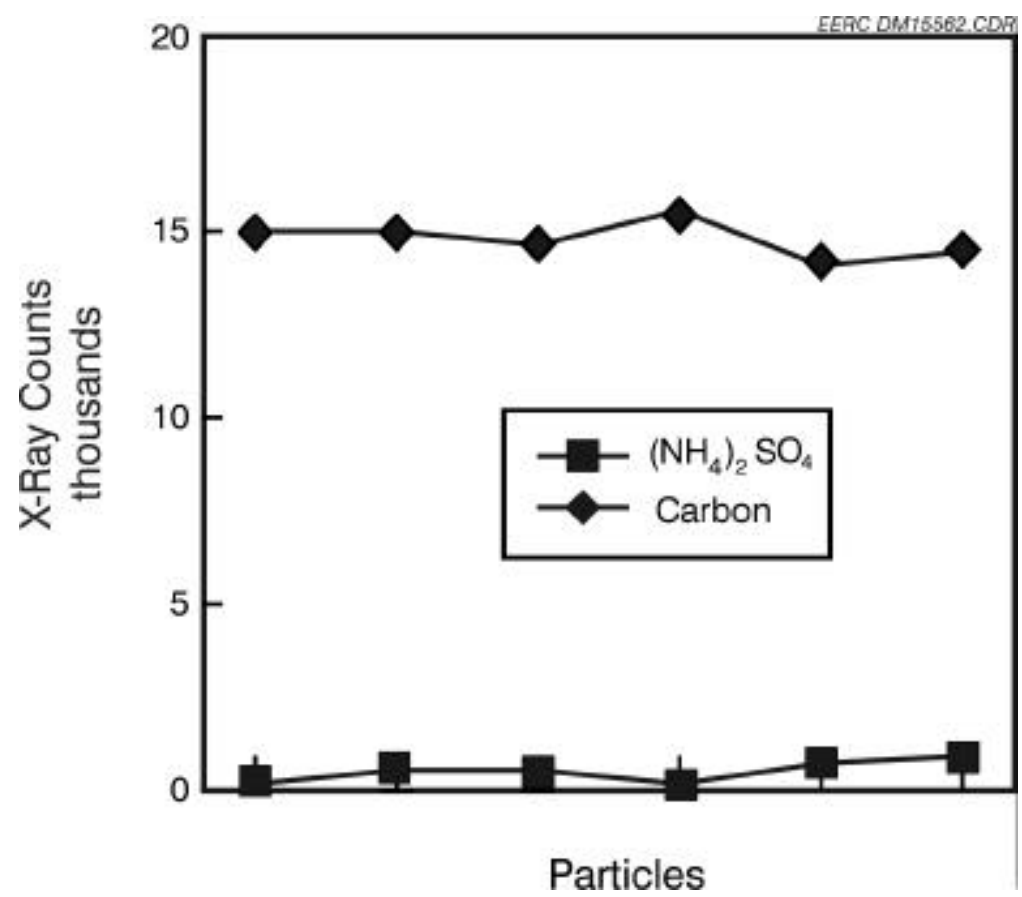

Figure 10. X-ray counts for $0.4-0.5-\mu \mathrm{m}\left(\mathrm{NH}_{4}\right)_{2} \mathrm{SO}_{4}$ particles. 
The beam parameters were optimized for analysis of light element, aerosol particles. An accelerating voltage of $5 \mathrm{kV}$, a beam current of $300 \mathrm{pA}$, and a magnification of 15,000× were determined to be the optimum parameters for the system used for this work and the type of samples encountered.

The reproducibility of the analyses is better for larger particles containing heavier elements. As the particle size decreased, the standard deviation increased.

The method of sizing by pixel area works very well as long as the SEM image is relatively sharp and particles are not touching each other. A poor quality image has an arbitrary cutoff for the particle edges, which affects particle-size analysis.

The signal vs. size plots show that even though conditions may be similar, the total counts tend to vary, especially in the intermediate sizes, while the particle counts may stay fairly constant.

\section{FUTURE PLANS}

The performance characteristics (particle-size limitations, precision, and bias) of the automated SEM method for chemically classifying and sizing individual particles in $\mathrm{PM}_{2.5}$ Samples will be evaluated by analyzing multicomponent aerosol standards. These multicomponent standards will be prepared using a precipitation procedure similar to that described by Haupt and others (Haupt, O.; Schaefer, C.; Strauß, S.; Dannecker, W. "Production of Calibration Standards for X-Ray Fluorescence Analysis of Aerosol Particles Precipitated on Different Filter Materials," Fresenius J. Anal. Chem. 1996, 355, 375-378). Assuming that the evaluation process indicates that automated SEM is useful for characterizing $\mathrm{PM}_{2.5}$, actual samples of $\mathrm{PM}_{2.5}$ collected from various ambient air-monitoring locations and point sources will be analyzed for source apportionment studies. 